\title{
Factibilidad, implementación y seguimiento temático en Colombia de la justicia especial para la paz frente a la estructura de la justicia transicional ${ }^{*}$
}

Recibido: 16 de septiembre del 2018 • Aprobado: 20 de noviembre del 2018

https://doi.org/10.22395/ojum.v17n35a2

\author{
Luz E. Mira" \\ Jahir A. Gutiérrez O.**
}

\section{RESUMEN}

El presente documento revisa la factibilidad, implementación y seguimiento temático de la justicia especial para la paz en contraposición con la justicia transicional en Colombia. La disparidad entre ambas formas de concebir la aplicación de la justicia en procesos de posconflicto induce a dicha revisión. Como método inicial, el diseño no experimental permite revisar la estructura de ambas formas de justicia; posteriormente se aplica el análisis complejo para abordar su convergencia o disparidad. Primero, se examina la composición de la justicia especial para la paz y de la justicia transicional. En una segunda instancia se caracteriza la complejidad de ambas formas de justicia en posconflicto. Finalmente, se explica la factibilidad, implementación y seguimiento temático de ambas con la finalidad de mostrar los impactos y resultados de estas.

Palabras clave: análisis complejo; diseño no experimental; justicia especial para la paz; justicia transicional; formulación e implementación; seguimiento a la justicia para la paz.

Este artículo es producto del proyecto de investigación "Retos de la justicia especial para la paz para garantizar el acceso a la justicia y la reparación integral de las mujeres víctimas de delitos de género, perpetrados con ocasión del conflicto armado en el departamento de Antioquia", aprobado en el 2018 por la Dirección de Investigación de la Institución Universitaria Tecnológico de Antioquia, llevado a cabo por el Grupo de Investigación Jurídico Social.

Abogada de la Corporación Universitaria De Sabaneta, Sabaneta, Colombia. Especialización en Tutela Jurídica de los Derechos Humanos de la Universitat Oberta de Catalunya, España; Especialización en Derecho Penal de la Universidad de Medellín, Colombia; Especialización en Derechos Humanos, Democracia y Globalización de la Universitat Oberta de Catalunya, España; Especialización en Derechos Humanos, Democracia y Conflicto de la Universitat Oberta de Catalunya, España. Maestría en Derecho Penal Internacional de la Universidad de Granada, España; Maestría en Derechos Humanos, Democracia y Derecho Internacional de la Universitat Oberta de Catalunya, España. Doctora en Ciencias Jurídicas de la Universidad Católica Santa María de los Buenos Aires, Argentina. Decana de la Facultad de Derecho y Ciencias Forenses del Tecnológico de Antioquia, ponente en eventos internacionales y docente universitaria para pregrado y posgrado. Líder del Grupo de Investigación Jurídico Social de la Institución Universitaria Tecnológico de Antioquia. Correo electrónico: luz. mira@tdea.edu.co Orcid: https://orcid.org/0000-0001-8686-0519

... Colombia. Doctor en Administración Pública, Atlantic International University (AIU), Honolulú, Estados Unidos de América. Categoría Investigador Asociado en el Departamento Administrativo de Ciencia y Tecnologia de Colombia (COLCIENCIAS). Miembro del Grupo de Investigación Jurídico Social de la Institución Universitaria Tecnológico de Antioquia. Miembro de la Asociación Colombiana para el Avance de la Ciencia (ACAC) y Par Evaluador Observatorio Colombiano de Ciencia y Tecnología (OCyt). Comisionado de Ordenamiento Territorial para el Departamento de Antioquia (2015-2019), Ponente Internacional, Docente Universitario e Investigador en Ciencias Jurídicas (Fuentes Auxiliares Formales del Derecho y Fuentes Auxiliares No Formales del Derecho). Correo electrónico: jagogutierrez@gmail.com Orcid: https://orcid.org/0000-0001-8564-0397 


\title{
Feasibility, Implementation and Thematic Follow-up in Colombia of the Special Justice for Peace in the Face of the Transitional Justice Structure
}

\begin{abstract}
This paper reviews the feasibility, implementation and thematic follow-up of the special justice for peace in opposition to transitional justice in Colombia. The disparity between both ways of conceiving the application of justice in post-conflict processes induces such revision. As an initial method, the non-experimental design allows to review the structure of both forms of justice: later on, complex analysis is applied to address their convergence or disparity. First, the composition of the special justice for peace and the transitional justice are examined. In a second instance, the complexity of both forms of post-conflict justice is characterized. Finally, the feasibility, implementation and thematic follow-up of both are explained in order to show their impacts and results
\end{abstract}

Keywords: complex analysis; non-experimental design; special justice for peace; transitional justice; formulation and implementation; justice for peace follow-up.

\section{Factibilidade, implementação e acompanhamento temático da justiça especial para a paz na Colômbia diante da estrutura da justiça transicional}

\section{RESUMO}

O presente documento revisa a factibilidade, a implementação e o acompanhamento temático da justiça especial para a paz em contraposição com a justiça transicional na Colômbia. A disparidade entre ambas as formas de conceber a aplicação da justiça em processos de pós-conflito induz a tal revisão. Como método inicial, o modelo não experimental permite revisar a estrutura de ambas as formas de justiça; posteriormente, aplica-se a análise complexa para abordar sua convergência ou disparidade. Primeiro, examina-se a composição da justiça especial para a paz e da justiça transicional. Em uma segunda instância, caracteriza-se a complexidade de ambas as formas de justiça em pós-conflito. Finalmente, explica-se a factibilidade, a implementação e o acompanhamento temático de ambas com a finalidade de mostrar os impactos e os resultados delas.

Palauras-chave: análise complexa; modelo não experimental; justiça especial para a paz; justiça transicional; formulação e implementação; acompanhamento da justiça para a paz. 


\section{INTRODUCCIÓN}

El conjunto de elementos que contiene la justicia especial para la paz y aquellos de la justicia transicional conllevan el interés de revisar la factibilidad, implementación y seguimiento que rodean a ambas formas de justicia. Básicamente tienen el mismo origen en tanto son producto de procesos de posconflicto, no obstante, sus directrices y lineamientos son diferentes entre sí, razón por la cual se conceptúa que no tienen la misma finalidad, y por ende, la conjugación de una u otra, más que clarificar, confunde. Es por ello que se pretende hacer una revisión de lo que contienen y qué tanto puede obtenerse de material relevante con el cual responder qué permiten ambas formas de justicia.

La amalgama entre justicia especial para la paz y justicia transicional ha traído consigo más incertidumbres que claridades en cuanto a la aplicación de la justicia para el posconflicto en Colombia.

Se considera que prevalece un cierto halo de improvisación o que esta responde a la construcción de una justicia de naturaleza exclusiva para el país. La realidad indica que para la justicia transicional prevalecen factores que han sido replicados en diferentes marcos de justicia en posconflicto. No obstante, se ha de revisar qué tanta fluidez hay entre ellas o grado de correspondencia, y con ello, dar parte de una posible complementariedad entre ambos aros de justicia.

Caracterizar cada una de las formas de justicia evidencia la capacidad y condi- ciones complejas que ostentan, se puede considerar así el grado de convergencia o disparidad que estas justicias esbozan. Por lo tanto, plantear el componente cibernético o estructural, a la par con la revisión del criterio de información relevante para un tema como este y la capacidad explicativa que exponen suponen medios para exponer que existen grados de convergencia y disparidad en temas puntuales, pero que en esencia, pueden cumplir básicamente lo mismo o superar temas de mayor trascendencia a lo esperado.

En consecuencia, como producto del documento, se pretende explicar la factibilidad, implementación y seguimiento que requieren ambas formas de justicia y exponer así que, más que congruencia o disparidad, es necesario blindar o justificar estas formas de justicia en la medida en que son instrumentos cuya capacidad no solo estriba en sancionar sino en estar en permanente contacto con la realidad conflictiva de las sociedades, las cuales deben pasar del diagnóstico a la postulación de diversos mecanismos encaminados a solventar las formas de conflicto que presentan y que superan la dilación conceptual o dispuesta.

La estructura del documento comprende los siguientes fundamentos: 1. La exposición de la estructura que rodea la justicia especial para la paz y la justicia transicional como fundamento para la justicia del posconflicto en Colombia; 2. El examen sobre el análisis complejo desde las fuentes cibernéticas, de información y sistémicas que rodean a ambas formas 
de justicia en posconflicto; y 3. La factibilidad, implementación y seguimiento que pueden tener ambas formas de justicia y los propósitos esperados. En el futuro, se espera efectivamente no quedarse inmersos en preguntas sobre el conflicto, sino también, dar paso a estudios sobre propuestas temáticas referentes a ello.

\section{ESTRUCTURA DE LA JUSTICIA ESPECIAL PARA LA PAZ Y LA JUSTICIA TRANSICIONAL COMO FUNDAMENTO PARA LA JUSTICIA DEL POSCONFLICTO EN COLOMBIA}

Se parte de la idea de mostrar los elementos, fuentes y variables que hacen dúctil la concreción de la justicia especial para la paz y la justicia transicional, ambas estimadas como fundamento para la revisión de la justicia aplicada en el posconflicto colombiano. El punto de partida radica en considerar la base de la justicia especial para la paz a la par de los elementos que rodean a la justicia transicional. Esto para finalmente exponer qué tanto peso tienen ambas fuentes de justicia para viabilizar la evaluación jurídica del posconflicto en Colombia, toda vez que se considera que es una apuesta del país, sin estructura perpetúa en ello.

Infraestructuras de paz son concebidas como un conjunto de espacios interconectados e institucionalizados, con responsabilidades asignadas por las partes de conflicto, mediante los cuales esas, junto con otros actores, construyen la paz y la sostienen en el tiempo. En varios países del mundo han probado ser muy útiles en diferentes momentos de conflicto y post-conflicto. Colombia vive ambos estados a la vez. Después de casi medio siglo de conflicto armado interno y tres décadas de esfuerzos de construcción de paz Colombia cuenta con mucha experiencia y buenos cimientos para el desarrollo de una infraestructura de paz. (Pfeiffer, 2014, p. 3)

El conflicto colombiano ha estado presente incluso desde la independencia, caracterizado por las pujas ideológicas o políticas más que emancipadoras o libertadoras, dado que no se han resuelto temas como la consolidación del Estado en toda su extensión y aún cuesta entender la magnificencia del concepto de nación o república en Colombia. Por ende, al tratar de plasmar lo que implica el análisis de un escenario como la justicia derivada en asuntos del conflicto -como en la actualidad con respecto al proceso de paz- es evidente la ausencia de elementos que permitirían extender, profundizar y recrear escenarios destinados a la concepción de una justicia para su consideración en los procesos de paz embarcados con los grupos beligerantes que se encuentran en conflicto con el Estado Colombiano.

La incorporación en Colombia de la justicia para el posconflicto establecida en la justicia especial para la paz ha dado como resultado una revisión del alcance, estructura, planteamiento y soluciones que esta puede engendrar, en una forma de justicia que solo aplica para el caso colombiano. De allí, la justicia transicional ha obtenido contenido, elementos y 


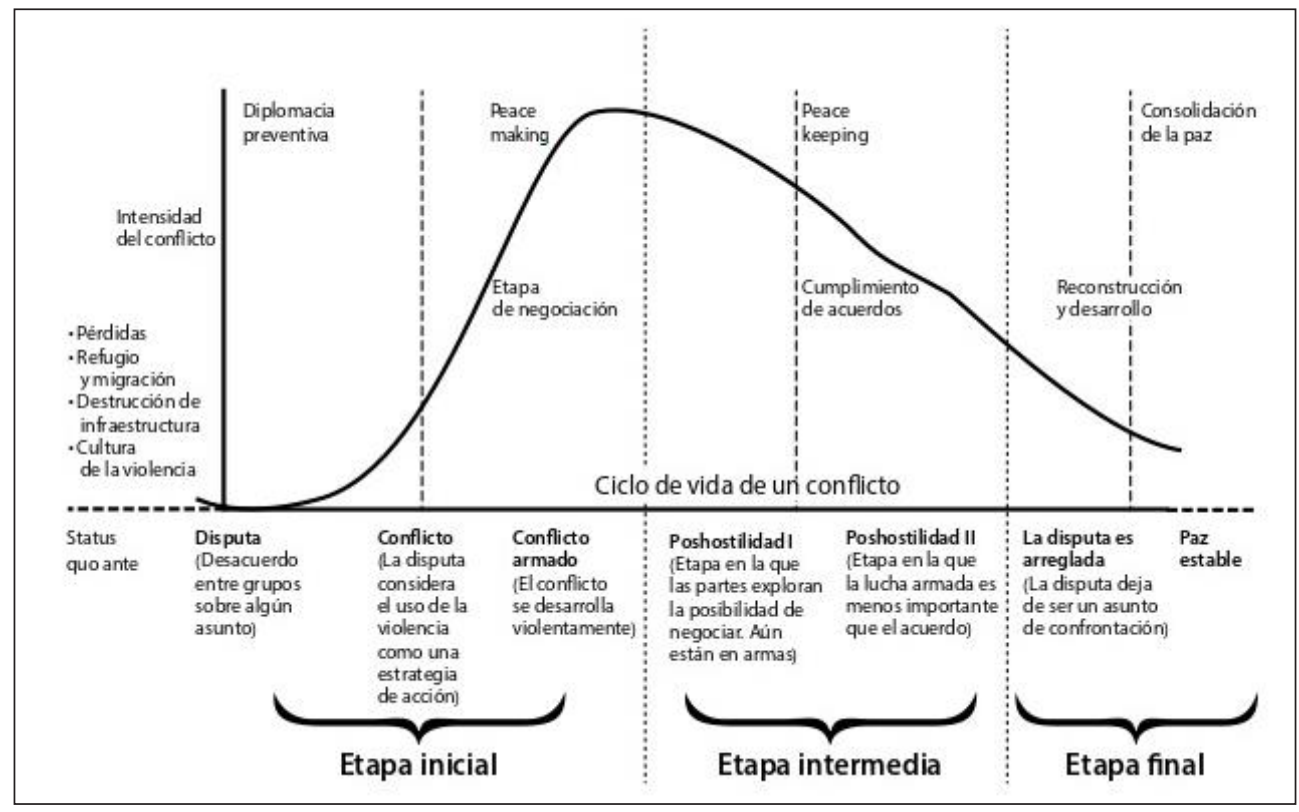

Figura 1. Etapas para el análisis y el manejo del conflicto colombiano. Acondicionamiento del modelo propuesto por Orozco en "De la negociación a la adaptación"

Fuente: Calderón (2016, p. 253)

trayectoria a la hora de poner en evidencia los resultados esperados en la justicia para el posconflicto. No obstante, resulta consecuente -más que adoptar una animadversión para con una u otra- exponer sus términos para sacar el máximo provecho o materializar resultados en ambos frentes de trabajo.

El caso colombiano: ¿justicia transicional sin transición? Las complejidades de la relación entre los estándares jurídicos de la justicia transicional y la política de las transacciones -y en particular de las transiciones negociadas- se agudizan en el caso colombiano. Esto es así no solo por las características particulares del conflicto armado colombiano y del contexto en el que se desarrolla, sino también porque en él se presenta una situación muy paradójica: a pesar de que el país está en medio de un conflicto armado aún en curso, el lenguaje de la justicia transicional es utilizado recurrentemente. (Uprimny y Saffon, 2007, p.166)

El inicio de cada forma de justicia en posconflicto parte de la idea de que cada Estado, nación o pueblo identifique la hoja de ruta más clara para poder dirimir las consecuencias o disparidades consagradas como esencia para la vigencia de los conflictos o la resolución de estos luego de un acuerdo o proceso de paz. La entrada en vigor de la justicia especial para la paz habla de la posibilidad de que se entienda la realidad de este suceso de cara a la realidad del país, más que de la 
imposición o importación de una réplica de justicia avanzada o exitosa a escala internacional. Es de la concepción de un modelo propio de justicia en el posconflicto que emerge la justicia especial para la paz.

Para que un Estado consiga un proceso de paz efectivo debe acoger los parámetros internacionales respecto de las garantías de no repetición dentro de su ordenamiento jurídico interno, haciéndolos mecanismos permanentes, desarrollándolos acorde con la realidad propia de la Nación en la que se apliquen. Es necesario tener en cuenta que este desarrollo no debe limitarse a crear normas e instrumentos jurídicos que los consagren, sino que simultáneamente deben crearse sistemas eficaces que permitan su aplicación dentro de todo el territorio en el cual se necesite y es necesario que estos sean conocidos por todos los ciudadanos. Si no se consigue que los mecanismos jurídicos para la obtención de la paz se lleven de la ley a la realidad y son se garantiza la no repetición, difícilmente se podrá trazar un camino diferente al de la Ley de justicia y paz, ello impediría la legitimación del Estado Social de Derecho y el fortalecimiento de las instituciones, paralizando la creación de una cultura de respeto a las instituciones democráticas y la consecución de un exitoso proceso de paz. (Duque y Torres, 2015, pp. 288-289).

Estas formas de justicia provienen de antecedentes contiguos en materia de procesos de paz y revisión de la justicia con cargo a los elementos a los que han dado origen. No obstante, a pesar de la diversidad del conflicto colombiano, la poca estructura de largo, o en consecuencia la individualización de cada uno de ellos, ha permitido que se considere que, con cada paso dado en la materia se presenten condiciones de improvisación o dilación a la hora de atender estos procesos. A pesar de ello, en Colombia se ha avanzado en la estructura, fuentes y mecanismos jurídico - legislativos con los cuales dar cuenta en cada proceso de paz o cierre de conflicto con algún grupo desmovilizado.

\begin{abstract}
La búsqueda de la verdad, en consecuencia, debe ir más allá de los procesos jurídicos. La reconstrucción de la verdad histórica y colectiva, la posibilidad de acudir a las narrativas de las víctimas y la sociedad en general y la construcción de una pedagogía de la memoria, a través de procesos de intervención con víctimas que les permiten empoderarse como actores sociales y políticos, serán fundamentales en la superación de la impunidad jurídica, principalmente de la impunidad social. (Pérez, 2013, p. 18)
\end{abstract}

Es por ello que no es propiamente una disparidad la que enaltece la diferencia conceptual, fundamental y propositiva de la justicia en posconflicto. En primer lugar, la justicia especial para la paz obedece precisamente a que el conflicto en Colombia no ha terminado, precisamente por la pervivencia de otros grupos al margen de la ley en conflicto con el 
Estado y la sociedad colombiana. Como segundo punto, la justicia transicional responde más a países que han superado por completo el conflicto interno e incluso es más de naturaleza internacional, es por ello que se trata de concebir una justicia propia del conflicto y cómo internacionalizarla.

\begin{abstract}
La experiencia internacional en la terminación de conflictos ha dado como resultado un documento denominado, "Los Principios de Chicago Sobre Justicia Transicional, donde se presentan directivas básicas para el diseño y aplicación de políticas para hacer frente a las atrocidades del pasado" (Bassiouni, 2007), que en nuestro país se ha ido implementando a través de la expedición de la ley de víctimas y restitución de tierras, entre otros decretos conexos, que dan aplicación en el papel a los Principios de Chicago sobre Justicia Transicional. (Niño, 2016, p. 146)
\end{abstract}

La posibilidad de hacer una distinción entre la justicia especial para la paz y la justicia transicional es el primer paso para sacar provecho de las ventajas que ofrecen ambos frentes de trabajo en la justicia de posconflicto. En ningún caso son excluyentes o reviste mayor relevancia una que la otra, contrario a ello, tienen su momento de aplicación y para el caso colombiano, en materia de justicia transicional, a pesar de la trayectoria adquirida por esta, no ha sido implementada, mas esto no significa que no haya un espacio para el desarrollo de una justicia especial para la paz con la posibilidad de reconstruir los puntos fundamentales que trazan el conflicto inconcluso de la realidad colombiana.

La justicia transicional es el vocablo preciso cuando se trata de conflictos de naturaleza internacional, además de ello, implica la remediación de los componentes que posibilitaron llegar a tal situación. Se parte entonces de que dicha justicia tiene potencial en la medida en que no se regresa de nuevo a ese conflicto, al igual que no se generará ningún tipo de represalia o dilación, y que, de ser el caso, se haría lo necesario para no recaer en dichos conflictos. Es por esto que la justicia transicional responde a criterios que están más enfocados en dar cuenta de las exigencias que a escala internacional se les pide a los Estados luego de superar sus conflictos.
El esclarecimiento de la verdad histórica es uno de los pila- res estructurales de la justicia transicional. En Colombia, la posibilidad de implementar una comisión de la verdad ha sido objeto de debates en tanto entre la doctrina internacional como en el seno de la sociedad civil co- lombiana considerándose como una verdadera opción para la superación del conflicto armado interno sin que haya llegado a realizarse. (Gutiérrez y Rodríguez, 2013, p. 40)

Es de suma prioridad clarificar que la reflexión que se hace al poner ambas formas de justicia en condición antagónica totalmente ilógica de cara a lo que implica la construcción o reconstrucción 


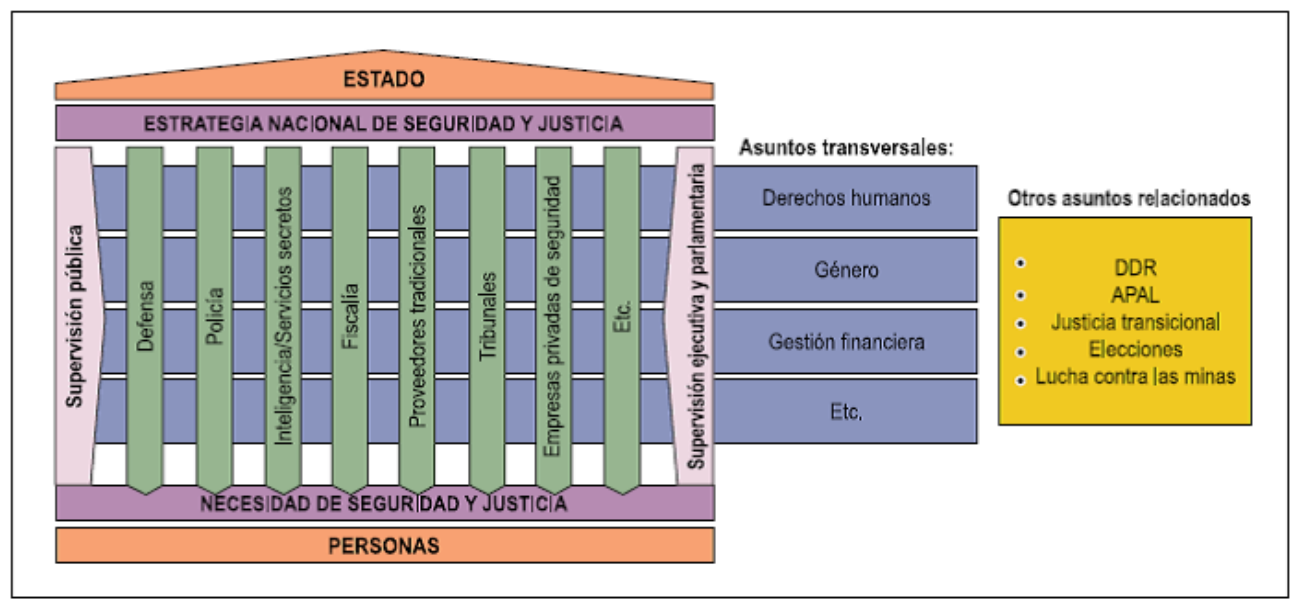

Figura 2. Modelo ideal e incompleto de agenda de construcción de paz que afecta al estado

Fuente: Rafael Grasa y Albert Caramés. 2016. Guía para abordar los procesos de DDR y de reforma del sector de seguridad en Colombia. ICIP. Barcelona/Bogotá (en curso de edición).

de la paz. En este caso, no solo se trata de hacer referencia a los modos de entender las metodologías idóneas para resolver los conflictos. Por ende, la apuesta radica precisamente en reconocer las distintas formas a través de las cuales se atienden tanto los conflictos vigentes como los posconflictos. Se reitera que en Colombia el diálogo y consecuente acuerdo de paz con un grupo al margen de la ley no pone al país en la condición de posconflicto, propio de países sin conflictos.

La Justicia Transicional se refiere a las labores que un Estado debe realizar cuando llega el posconflicto y carga consigo el legado de graves violaciones a los derechos humanos, o lo que ella misma ha señalado: el paso del autoritarismo hacia la paz, a través de etapas de transición política que requieren el restablecimiento de la democracia. Frente a la aplicabilidad de la Justicia Transicional en Colombia, debe tenerse en cuenta que, aunque éste [sic] sea un Estado social y democrático de derecho, no ha superado los factores generados de violencia que permiten considerar la existencia de un postconflicto y la legitimación de un Estado de Derecho, por lo que surgen varios interrogantes ¿Por qué hablar de Justicia Transicional?, ¿qué puede aportar al estudio del conflicto en Colombia? (Lopera, 2011, p. 2)

Es importante que se haga claridad con respecto a la no aplicación de la justicia transicional por los aspectos ya esgrimidos. No solo incide la dificultad conceptual que ha rodeado el marco de referencia de los tipos de justicia en los conflictos, dado que estos no solo son regulares cuando se trata de temas internacionales, irregulares cuando se trata de conflictos internos -e incluso 
por cuenta de grupos que se derivan al margen de ambos frentes-, y que aún son contemplados por fuera del origen del conflicto. Básicamente, se trata de reconocer que los conflictos son una constante y que la sola alusión a sus diagnósticos no es consecuente, también se debe trabajar en su análisis.

La justicia transicional durante mucho tiempo se entendió como un modelo de justicia necesario para la transición de regímenes autoritarios hacia sistemas democráticos, así como para la superación de guerras internacionales en la búsqueda de la paz. Sin embargo, hoy en día los alcances de este modelo han variado para fortuna de diferentes países, que, como Colombia, sufren y han vivido los denominados conflictos internos. Se ha definido la justicia transicional por parte del Consejo de Seguridad de Naciones Unidas como un modelo que: [a]barca toda la variedad de procesos y mecanismos asociados con los intentos de una sociedad por resolver los problemas derivados de un pasado de abusos a gran escala, a fin de que los responsables rindan cuentas de sus actos, servir a la justicia y lograr la reconciliación. Tales mecanismos pueden ser judiciales o extrajudiciales y tener distintos niveles de participación internacional (o carecer por completo de ella) así como abarcar el enjuiciamiento de personas, el resarcimiento, la búsqueda de la verdad, la reforma institucional, la investigación de antecedentes, la remoción del cargo o combinaciones de todos ellos. (Consejo de Seguridad de las Naciones Unidas S/2004/616, 2004)
La legislación colombiana ha determinado construir un modelo de justicia transicional, a pesar de la perduración del conflicto bélico no internacional, contrario al modelo tradicional, el cual genera disposiciones y estructuras transicionales en la etapa de posconflicto. Este ejercicio en Colombia asume sus riesgos, pero puede ser conveniente si las partes hacen un des-escalamiento de la guerra de manera racional y efectiva. Para ello, se han elaborado una serie de mecanismos jurídicos tanto legislativos como judiciales, tratando de brindar una suerte de legitimidad institucional a los acuerdos y a los procesos suscitados entre las partes del conflicto en Colombia. (Sabogal, 2017, pp. 215-216)

Se considera entonces que, en ambos frentes de trabajo, se extiende el aporte que hace cada una de las formas de justicia para el conflicto y posconflicto. Los diversos marcos de justicia para el conflicto exponen que para cada caso o dificultades con los grupos al margen de la ley contrarios al Estado se requieren estos mecanismos por la mutación que presentan. Los procesos en posconflicto dan cuenta de elementos que en la mayoría de los casos, pueden ser nuevos para la realidad colombiana, a diferencia de la suma de procesos de paz llevados a cabo en Colombia de los cuales se deberían recoger enseñanzas y puntos para materializarlos en procesos concluidos sobre la base de dicha justicia. 
El concepto de justicia transicional se comienza a implementar a mediados del siglo XX después de la Segunda Guerra Mundial, en la cual fue necesario utilizar mecanismos de justicia para hacer frente a las atrocidades cometidas durante el conflicto. Entre estos mecanismos de justicia se destacan los hechos juzgados por el Tribunal de Núremberg y el intento de establecer la democracia y la institucionalización del Estado de Derecho. Ahora bien, debe señalarse que el término tuvo sus primeras manifestaciones frente a temas y transformaciones puramente políticas. De esta forma, cuando se habla de justicia transicional, el concepto de transición generalmente se refiere a una transformación política significativa y a una ruptura con el pasado, lo cual ayuda a fortalecer el proceso de equidad. (Carrillo, 2015, p. 11)

En consecuencia, tanto la justicia especial para la paz como la justicia transicional son dos elementos que se deben relativizar en la realidad colombiana. Con respecto a la primera, se puede indicar que parte de la idea de recomponer el actual proceso de paz con diversos grupos en conflicto con el Estado colombiano y que dan cuenta para cada caso que la justicia en procesos de paz debe ser dinámica. En cuanto a la segunda, obedece más a un orden estructural en la medida en que el Estado colombiano siempre ha estado inmerso en conflictos, por lo tanto, siempre ha debido contar con una estructura constante de cara más que al diagnóstico y a la formulación de propuestas viables.

\section{REVISIÓN COMPLEJA DE LAS FORMAS DE JUSTICIA EN CONFLICTO Y POSCONFLICTO EN COLOMBIA DESDE LAS FUENTES CIBERNÉTICAS, DE INFORMACIÓN Y SISTÉMICAS DEL ANÁLISIS COMPLEJO}

El análisis complejo goza de tres fuentes de conocimiento a través de los cuales resuelven o propugnan por los paradigmas que lo explican. Las fuentes establecidas son: la teoría cibernética o de regulación entre objetos y propósitos; la teoría de la información, cuya idea es fundamentar el origen de cifras, datos o información incompleta en materia de la temática que se está considerando; y finalmente, las estructuras a través de las cuales se justifica la interacción en el campo de interés tratado bajo dicha metodología, como en el caso de las formas de justicia para el conflicto o posconflicto en el que se encuentra inmerso el país.

Con el objetivo de entender la forma en la que se viene implementando este modelo de justicia transicional sui géneris -cuya singularidad se debe a la complejidad del conflicto colombiano- y ante la masiva vulneración de los derechos de las víctimas en los procesos de transición (siendo estas quienes resultas más afectadas), la investigación se enfoca en determinar la forma en que se garantizan los derechos de las víctimas del conflicto armado colombiano en el marco de la justicia transicional, y tiene como objetivo analizar los mecanismos jurídicos implementados por el Estado a fin de garantizar los derechos humanos de las víctimas del conflicto armado en Colombia (Carrillo, 2015, p. 11) 
La complejidad del conflicto colombiano ha permitido que se avance, por lo menos en cuanto al diagnóstico planteado sobre las razones en las que aún no se sale de la situación. La incompatibilidad de pensamientos entre los hacedores de la campaña libertadora (Bolívar - Santander), la inexistente definición de un contrato social claro entre el Estado y la sociedad -en el que el primero es quien ha construido prácticamente la idea de sí mismo por sí solo-, y la consecuente aparición de conflictos provenientes de diversas latitudes del país hacen de Colombia un laboratorio propio para todas las formas de justicia en conflicto y posconflicto.

En el marco de procesos de paz o de transición a la democracia no puede desconocerse la obligación internacional de investigar, juzgar y condenar las graves violaciones a los derechos humanos y el Derecho Internacional Humanitario. La existencia de un programa de justicia transicional interno no limita el acceso a la jurisdicción interamericana y tampoco impide que esta investigue o determine la responsabilidad del Estado por acción u omisión, en presencia de graves violaciones de derechos humanos o de otro tipo de casos, ya sea por agentes estatales o por parte de grupos armados al margen de la ley. (Ventura, 2016, p.49)

Es por ello que es necesario plantear qué tanta carga en materia de regulación, información y sistematicidad posee la justicia en conflicto o posconflicto. De la posibilidad de contar con dichos frentes, se puede rastrear efectivamente que lo logrado o propuesto en ellas permite alcanzar los impactos y resultados esperados. Así, si bien hay material de análisis con respecto a la justicia transicional como prueba de los logros obtenidos en la materia a escala internacional, en materia de la justicia especial para la paz, los tres frentes acotados constituyen la primera tarea que debe articular o derivar para que cada uno de los temas expuestos por la Jurisdicción Especial para la Paz (JEP), tengan asiento y eficacia.

$$
\begin{aligned}
& \text { La Constitución Política de } \\
& \text { Colombia consagró en su artí- } \\
& \text { culo } 22 \text { la Paz como un derecho } \\
& \text { y un deber de todo colombiano, } \\
& \text { y a partir de este concepto se } \\
& \text { desarrollan todas las políticas del } \\
& \text { gobierno nacional, en respuesta } \\
& \text { a los conflictos que se presentan } \\
& \text { actualmente. La paz se construye } \\
& \text { entonces en el fin último de las } \\
& \text { políticas nacionales en materia } \\
& \text { de inclusión social, reintegración, } \\
& \text { justicia transicional, derechos } \\
& \text { humanos y derecho internacional } \\
& \text { humanitario. (Zúñiga, 2017, p. 119) }
\end{aligned}
$$

En términos generales, se debe considerar que las formas de justicia en conflicto y posconflicto se convierte en el primer esfuerzo al que se debe atender para abordar la realidad colombiana. Si bien se considera como una suerte de Estado fallido por la cantidad de conflictos que maneja - dispares entre sí y poco consecuentes en sus propósitos-, la realidad es que en Colombia la construcción de ambos frentes de trabajo se convierte en el primer propósito para poder hacer frente a la relación variopinta del conflicto 
colombiano; no sin desconocer que ambas formas de justicia contempladas terminan siendo complementarias y transversales a las formas de justicia.

\begin{abstract}
Colombia, ¿una sociedad postconflicto? En este punto de la argumentación es posible establecer una conclusión parcial, Colombia no es una sociedad postconflicto y la aplicación de las estrategias de la justicia transicional se dio fuera de contexto. Si ocurrió una desmovilización de los actores armados, ésta [sic] tuvo un carácter parcial, porque no participaron en ella todos los miembros de las AUC; además, las FARC estuvieron completamente marginadas del proceso. (Rodríguez, 2015, p. 150)
\end{abstract}

Es la historia del conflicto armado colombiano regular y las diferentes formas de acercamiento, diálogo y resultados obtenidos, lo que da la carta abierta al país para afincarse más en la justicia especial para la paz que en la transicional. Es decir, la no solución plena del conflicto, pero sí el paulatino ascenso de solución de conflictos uno a uno en el país, hacen del Estado colombiano y al propio sistema de justicia una especie de sustanciadores, cuya capacidad radica en poder orientar las negociaciones que vienen de manera concreta, aunque no estructural. Es una causa intacta, pero que no encuentra un único camino dadas las experiencias anteriores.

El fundamento que sustenta la incorporación de la justicia en conflicto o posconflicto debe pasar precisamente por el reconocimiento de ambas circunstancias por parte de la sociedad más que por el propio Estado que aún debe ser garante pleno de cualquier circunstancia que conduzca a la desaparición de los conflictos. Por ende, el llamado a la construcción de memorias históricas, el levantamiento de antecedentes o la búsqueda de la población afectada, no solo para compensarla sino para reconocer la narrativa del conflicto, hacen de la justicia especial para la paz el centro de dicha consideración, de cara a la formulación de la regulación, la información y las propuestas.

Tabla 1. Resumen de la dimensión del conflicto armado colombiano

Dimensión del conflicto armado colombiano

\begin{tabular}{ll}
\hline Datos generales & $\begin{array}{l}\text { El hecho que más provoca víctimas es el desplazamiento con } 6044 \\
151 \text { víctimas, 85\% de ellas corresponde a este fenómeno. Le sigue } \\
\text { el homicidio, con } 931720 \text { casos y después la amenaza (213 694) y la } \\
\text { desaparición forzada (152 455). }\end{array}$ \\
\hline $\begin{array}{l}\text { Principales territo- } \\
\text { rios afectados }\end{array}$ & $\begin{array}{l}\text { Antioquia es el departamento del país con mayor número de víctimas, } \\
1433483, \text { seguido de Bolívar con } 530889 \text { y Magdalena con } 430787 .\end{array}$ \\
\hline
\end{tabular}

Fuente: elaboración propia a partir de los datos de Reconciliación de Colombia (2014) citados por Calderón (2016, p. 237) 
En la última entrevista concedida antes de su muerte, ya Foucault, daba algunas pistas sobre los nuevos escenarios que se posicionarán más claramente: el proceso de globalización, las nuevas formas de exclusión y su relación con el poder y la verdad; son pistas de investigación, un trabajo que se elaboró acudiendo a las voces de las víctimas entrevistaldals en el proyecto Familias y construcción de memorias, pero son eso solamente eso, líneas de un trabajo que es reciente en el país, sobre las víctimas y con las víctimas, en las cuales, la verdad, la justicia y la reparación, se está construyendo muy lentamente. (García, 2012, p. 84)

Bajo la justicia especial para la paz el Estado colombiano está enfocado en elevar el conflicto colombiano a la consideración, evaluación, juicio y resolución por cuenta de dicha justicia. Los antecedentes presentados con los grupos al margen de la ley, contra e insurgentes han sido la base para exponer el fundamento de una justicia enfocada en reducir los diversos conflictos que caracterizan a la realidad colombiana, más aun cuando estos terminan derivando en otros. Por ende, la serie de encuentros, mesas y procesos de paz a los que ha incurrido el Estado colombiano cuenta con la base jurídica para atenderlos en propiedad, de cara a un sistema permanente y no ocasional.

Desde hace algo más de dos décadas, la normatividad expedida para dichos efectos no incluía, tal y como $1[0]$ hace la Ley de Justicia y Paz, al menos en sentido formal, asuntos transversales a una iniciativa de paz como son las víctimas de la confrontación y sus derechos, ni condenas con el beneficio de una pena alternativa, pues las únicas figuras aplicables -y objeto de regulación-, eran la amnistía, y el indulto como aspectos estructurales de tales normas. (Valencia y Mejía, 2010, p. 62)

Desde la teoría de la información se busca precisamente disponer de la mayor cantidad de cifras, datos y metadatos con los cuales se pueda estructurar, formular y materializar elementos con los cuales trabajar en cada uno de los tipos de justicia en conflicto o posconflicto. En este caso, se trata de pasar del diagnóstico a la composición cifrada de mediano o largo plazo, a la par de la consecuente revisión y cotejo de datos con hechos para sacar el mejor provecho de las circunstancias que han rodeado los procesos de paz o la misma incorporación de diferentes tipos de justicia. En este caso, se exponen igualmente las debilidades de ambos tópicos en Colombia.

Lo que se corrobora es la existencia del evento violento mismo, y en lo posible, sus "autores materiales", mediante la indagación o clarificación de las "circunstancias de modo, tiempo y lugar" de los "hechos delictivos", y por supuesto el "daño" en el marco de las operaciones de grupos ilegales. Esta triangulación entre "modo", "tiempo" y "lugar" permite que el escenario de responsabilidades penales recaiga, si el responsable directo no existe, sobre el jefe del Frente que operaba en la época del hecho que se investiga. (Castillejo, 2014, p. 220) 
Se espera que la justicia especial para la paz exponga en concreto los elementos con los cuales pasar de la memoria y la pena a las formas de resolver las razones que generaron el conflicto. En este caso y de manera clara, se analiza la posición sistémica en la que recaería la toma de decisiones, no solo para avalar todo lo contemplado en el tipo de justicia, sino para que esta sea comprensible. En consecuencia, la responsabilidad de la justicia en conflicto radica precisamente en explicar de la manera más diáfana posible, las razones con las cuales se espera avanzar en materia de justicia en conflicto y cómo en cada caso siempre se plantea una razón institucional para lograrlo.

¿Cómo se "certifica" (técnicamente) el "daño" que produce la guerra en una sociedad o en una persona? ¿Dónde se "localiza" la violencia, en qué espacios geográficos, productivos, corporales, subjetivos o sensoriales?[,] o cen qué temporalidades? ¿En el "pasado histórico", en el pasado de "largas temporalidades" o en el "presente permanente" que se mueve hacia el futuro? ¿Cómo se le asigna a un nombre, una imagen a una experiencia "daño" o a los rastros que produce?, Este texto comienza, en cierto sentido, por el final. Por las imágenes de prendas y restos humanos producto de la investigación de personas desaparecidas en el marco de la Ley de Justicia y Paz en Colombia. (Castillejo, 2014, p. 215).

Un balance claro entre la comparación de la justicia especial para la paz con la propia Ley de Justicia y Paz frente a la justicia transicional, es que la primera recoge la impronta de las dos últimas para sacar el máximo provecho del tipo de justicia especial para la paz que se requiere. Por ende, no hay una tipología que sea mejor que otra, sino la capacidad que se requiere de estas para obtener los mejores resultados. Por ello, podría decirse que la Ley de Justicia y Paz sirvió de base para el marco regulatorio, la justicia transicional para lo que implica la información, y la justicia especial para la paz está abocada a responder desde el punto de vista sistémico al conflicto colombiano.

En varios países, tales como el Salvador, Argentina y Colombia, la justicia transicional se ve impedida para funcionar debido a una serie de situaciones reiteradas, tales como la falta de independencia judicial; la dilación de procesos por parte de intervinientes; la discriminación de las víctimas por parte de la administración de justicia; la incredulidad de la sociedad víctima de grandes violaciones frente al aparato de justicia. En la realidad colombiana, en concreto, y según numerosos estudios y evidencias, la justicia transicional no ha logrado de ninguna manera lo que en esencia se ha propuesto, dado que en la práctica no solo no se han visto los resultados de las estimulantes penas para los condenados en la consecución de la desmovilización de los grupos armados, sino que, además, se continúa sacrificando los derechos de las víctimas. (Torregrosa Jiménez, R., Torregrosa Jiménez, N., y Manrique, 2015, pp. 103-104) 
La justicia transicional no alcanzó a mostrar su marco regulatorio, o por lo menos su capacidad para explicar por completo la justicia requerida en conflicto para el caso colombiano. Seguido a esto, tiene dificultades para recabar cifras, datos e información por cuenta de los variados intereses creados el amparo de dicha justicia en la cual cada actor se sintió víctima o fue considerado victimario de manera directa, sin una etapa previa en la cual se destacaran fundamentos para ello, y finalmente, no se logró - por lo menos para el caso colombianovisualizar la hoja de ruta, esquema u orientación con el cual poder obtener los mejores réditos a partir de su aplicación en el país.

Se mostrará qué como tal no existe un arquetipo ideal de justicia transicional, que sus resultados no son siempre los esperados, y que por lo mismo, la sola implementación de ésta [sic] fórmula jurídica es insuficiente para lograr la transformación social requerida para superar la violencia y avanzar en la construcción de un nuevo país. Pese a sus aciertos en términos de desarticulación de los grupos armados, la justicia transicional deja un sabor amargo al revelar sus límites a la hora de afrontar problemas estructurales como la impunidad, la corrupción y la exclusión social, que requieren, antes que una flexibilización del derecho penal, un compromiso nacional construido sobre la voluntad real de los gobiernos, los actores armados, las víctimas y la sociedad en general. (Rodríguez Montenegro, 2011, p. 53)
Es por esto que se debe revisar la hoja de ruta adoptada por el Estado colombiano, que en esencia y por encima de la propia sociedad se ha abocado a revisar desde la justicia para la paz e incluso antes de esta, los posibles procesos con los cuales atender el conflicto. A su paso, con la Ley de Justicia y Paz, también tuvo la capacidad para dar cuenta de grupos irregulares o contrainsurgentes con el propósito de menguar jurídicamente las diásporas del conflicto colombiano, y ahora el cerco de este, en pos de cerrar la brecha entre los insurgentes y los más afectados, como es la población que registró sufrir el mayor peso del conflicto perpetrado por cada uno de ellos.

\section{LA FACTIBILIDAD, IMPLEMENTACIÓN Y SEGUIMIENTO DE LA JUSTICIA ESPECIAL PARA LA PAZ EN CONFLICTO EN COLOMBIA}

Identificar los resultados de la justicia especial para la paz solo dependerá de la capacidad argumentativa, descriptiva y explicativa que esta exponga en los temas incorporados al paso de dicha justicia, entre los cuales se cuenta la sala de derechos ambientales, derechos humanos y derechos de género, en términos generales. Frente a estos derechos, se debe plantear el camino para estructurar las bases, tal que luego de que se apruebe de manera conforme, se pueda implementar el tipo de justicia especial para la paz aplicada a través de ellos, y posibilitar que dicho proceso sea evaluado, seguido y controlado de cara a cumplir con los preceptos contemplados en esta justicia. 
La justicia especial para la paz se centra más en la sociedad civil que en los actores del conflicto, por cuanto pone en condición de igualdad a los que, desde diferentes orillas del conflicto, padecieron o padecen sus consecuencias y en cada caso, no tuvieron espacio para ser considerados dentro de los procesos del pasado, la Ley de Justicia y Paz o la actual, e incluso de la expuesta por la justicia transicional. Por ende, es la sociedad civil la que velará porque efectivamente se haga seguimiento, más que a los acuerdos de paz - que es un asunto entre el Estado y los grupos al margen de la ley-, a la resolución del conflicto, es la sociedad la que vela por superarlo.

\begin{abstract}
Se podría sintetizar que la paz territorial es el proceso de transformación de los territorios en clave de justicia social, a partir del reconocimiento de las trayectorias históricas de los sujetos allí actuantes y las diversas características de los conflictos existentes, mediado por sendas apuestas de autor organización social, económica, cultural y ambiental protagonizados por las comunidades. (Bautista, 2017, p. 109)
\end{abstract}

En cuanto a la factibilidad, la aparición de esta forma de justicia especial para la paz es un hecho reciente que ha superado el debate de las anteriormente planteadas, pero con cargo o basadas en ellas. Se trata entonces de materializar una justicia verificable por fuera de los estrados, toda vez que los magistrados a cargo de la justicia especial no pueden ser en ejercicio ni tener causas pendientes en materia de procesos derivados del conflicto. La disposición de dichos magistrados, al igual que la constitución de las salas enfocadas en solventar los derechos consagrados en la justicia especial para la paz, es el avance más relevante, ahora debe iniciar su acción.

\begin{abstract}
Así, la etnografía, en un sentido relacional, permite que los casos y las experiencias particulares den cuenta no sólo [sic] de su inscripción o distanciamiento de determinados tipos ideales, si no que se convierte en la evidencia de los l[ílmites conceptuales, discursivos y materiales de los tipos ideales con los que esperamos establecer las conexiones entre Estado y sujeto, o entre agencia y estructura. (Jiménez, 2008, p. 46)
\end{abstract}

Es así que la justicia especial para la paz puede ser considerada una etapa superior de los procesos de paz anteriores planteados en el país. Si bien la lectura de una y otra forma de justicia para el conflicto o posconflicto será una constante, en esencia, no es lo trascendental del debate, sino la manera en que este proceso se saca adelante, derivado de un proceso de paz. No obstante, se requiere seguir trabajando en dicho tema de forma estructural porque en términos institucionales, resulta productivo contar con una justicia especial para la paz que esté expuesta no solo a un tema puntual, sino que sirva para los demás procesos que vienen en camino, y se pueda así generar institucionalidad. 


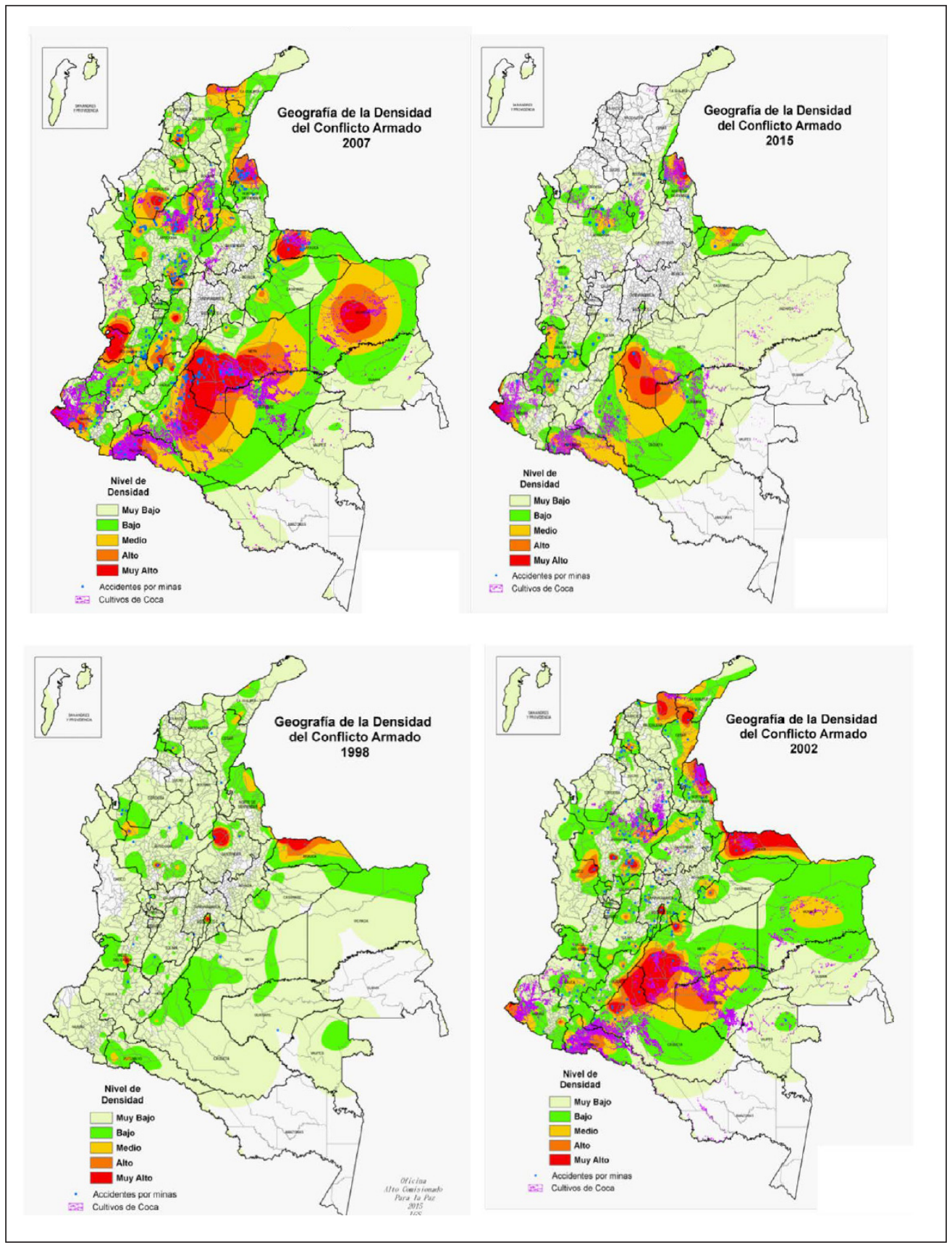

Figura 3. Dinámica multitemporal de la afectación territorial del conflicto armado en Colombia.

Fuente: Boletines de Orden Público del DAS, Boletines de Prensa FFMM, ISA, Ecopetrol y Prensa Nacional - Regional, Simci - Onudc. Cartografía Básica. 
Señalamos cómo para el caso colombiano, en el actual terreno del proceso de Justicia y paz, ambas dimensiones generan tensión y disputa. Nuestra pregunta aquí es ¿Qué tantas miradas de forma imbricada, ponderando reflexivamente sus contenidos filosóficos y sus costos políticos, podrían o no garantizar un "equilibrio necesario" en la aplicación de medidas transicionales más efectivamente, a las que tenemos hasta ahora en el país? (Jaramillo y Delgado, 2011, p. 130)

El conjunto de temas arropados por la justicia especial para la paz como los comentados, no hacen parte en esencia de los tópicos consagrados en el conflicto, toda vez que se toman como delitos perpetrados como consecuencia del conflicto armado, pero en ningún caso, terminan por reportar el beneficio, impacto o resarcimiento a la población afectada. Si bien prevalecen condenas o emergen estas de cara a los insucesos fruto del conflicto, estos son tratados más como asuntos propios de las partes, sin aventurar a incorporar a la sociedad como la más afectada. Es por esto que los temas ambientales, de derechos humanos y género, tendrían sala e intereses propios.

Debido al desplazamiento forzado a muchas mujeres colombianas se les abre una nueva perspectiva de vida en la cual ellas tienen que asumir responsabilidades que no tenían antes y en la que pueden ser más participativas a nivel político y social. Es preciso realizar trabajos de campo que contribuyan a mejora[r] sus opciones de vida. La metodología cualitativa puede ser de gran ayuda para realizar procesos de intervención de modo que terminen fortalecidas y empoderadas en su nueva realidad. (Romero y Contreras, 2015, p. 79)

En cuanto a la implementación, se requiere reconocer que gran parte del capital burocrático y de recursos públicos en distintas instancias han terminado por agolparse en materia del proceso de paz. En esta dirección, se entiende que la justicia especial para la paz igualmente requiere una recomposición en la estructura burocrática y presupuestal del Estado colombiano. No se trata solo de hacer restablecimiento de derechos o equilibrio de instancias jurídicas para la paz, sino de establecer los mínimos y máximos para no recaer en procesos similares y que más aún, se debe verificar que efectivamente sea la sociedad la que verifique lo que se realice mediante la justicia especial para la paz.

Sin embargo, aun cuando se trata de un problema que ha superado con creces la capacidad de respuesta del Estado, no por ello se puede caer en el escepticismo y la desesperanza, ni evadir la responsabilidad histórica que le compete a la academia en el interés de conocer y comprender los fenómenos socio - jurídicos de sociedades altamente convulsionadas como la nuestra, además de proponer alternativas de solución y aportar a la construcción de una mejor sociedad. (García, 2012, p. 84) 
La implementación corre por cuenta de las políticas públicas con enfoque de derechos jurídicos, poblacionales y territoriales con las cuales poner en evidencia que efectivamente lo contemplado en la justicia especial para la paz se aplique, por encima de la discrecionalidad de las salas o los magistrados a cargo de la justicia especial para la paz. Es decir que, en las salas también deben prevalecer no solo el sustento, justificación y veredicto jurídico, sino también la capacidad de respuesta por la vía de la política pública que corresponde a los actores acoger para sacar adelante los baches del conflicto, y que, de contemplarse, podría pasar de la revisión de la justicia a sus resultados.

La implementación debe pasar por ambas fuentes de aplicación bajo las estrategias top down de orden institucional y las de bottom up de orden poblacional. Es una combinación de las dos con el propósito de verificar en ambas vertientes la capacidad de ajuste, reconfiguración o modulación que pueden tener ambos frentes para responder a los preceptos de la justicia especial para la paz y de paso, formular políticas públicas encaminadas a solventar lo planteado de manera interinstitucional y con diversos actores. Se trata de abordar el conflicto desde un marco de respuesta interinstitucional y para ello, se requiere hacer un recuento de las instituciones para dicho propósito.

Se acuña que hay un desembalaje desde lo externo (internacional) y lo interno (nacional), que surge en lo cultural un recambio en la mentalidad desde el individuo y no desde la norma como las manifestaciones para citar un ejemplo, que se reconocen sus derechos desde lo inductivo como actores legítimos con un resultado de un grupo presión multicultural que se reconocen en una escala de justicia infra estatal interactuando como clases emergente dentro del desarrollo global. (Garzón, 2013, p. 180)

En cuanto a los magistrados y salas contempladas en el marco de los derechos ambientales, humanos y de género, se ha de destacar que por primera vez, se abren salas propias a expensas del sistema de justicia con capacidad de concentrarse, dirimir y generar resultados concretos para la justicia especial para la paz. En cada uno de estos derechos se han generado daños severos y ha habido poca revisión de los impactos y resultados que conlleva esta situación y que paradójicamente, antes eran considerados concomitantes por cuenta del conflicto, precepto alejado de toda la realidad colombiana, y ni que decir, a la hora de verificar la superación de dichos frentes en propiedad.

El proceso de elaboración de una
Constitución ofrece a la sociedad
organizada la oportunidad de es-
tructurar el Estado a incidir en las
normas que garantizan derechos
y resguardos para poder exigir
su cumplimiento. (Montaño y
Aranda, 2006, p. 13)

El seguimiento que se debe hacer a cada uno de dichos magistrados, salas y 


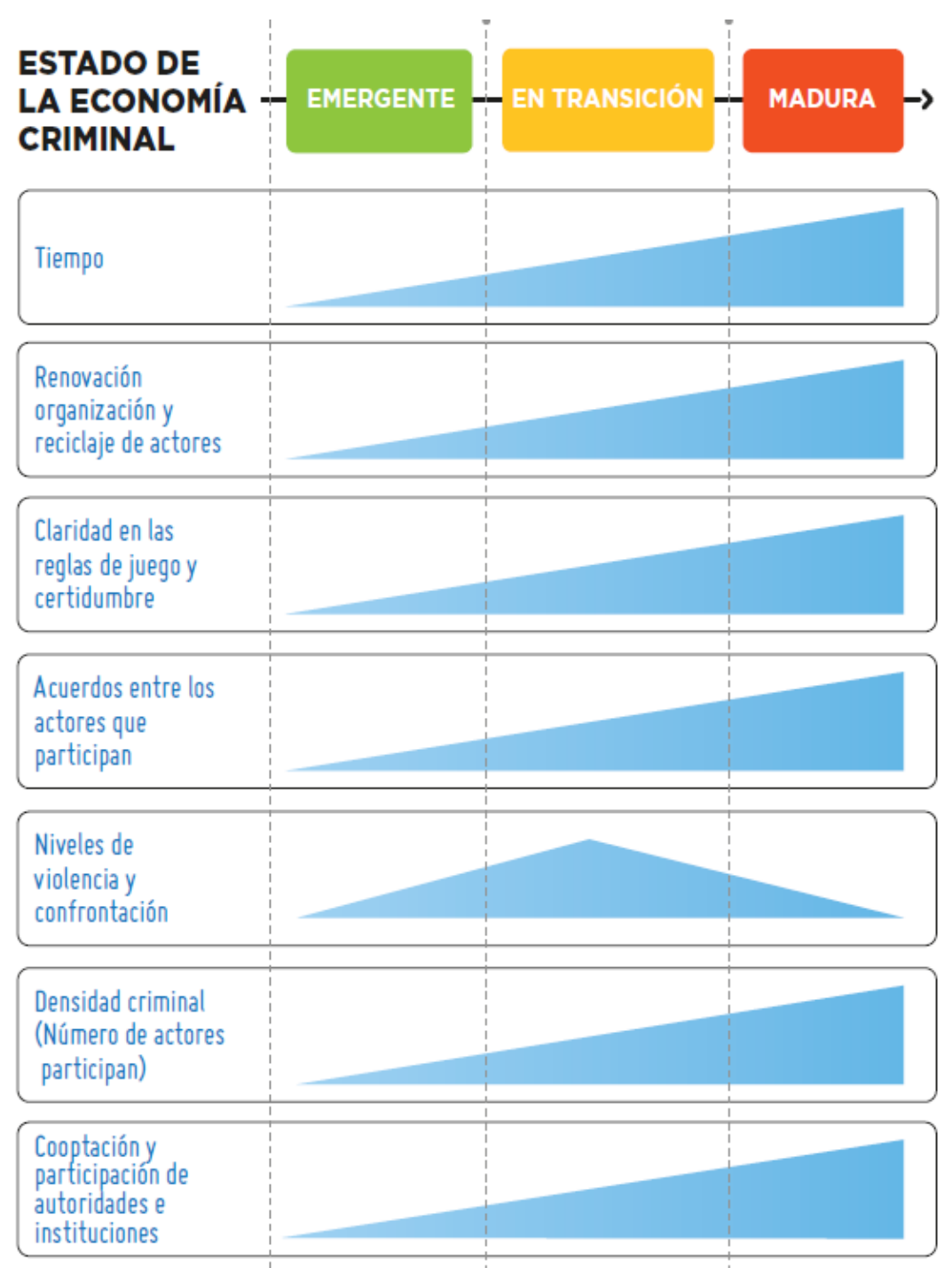

Figura 4. Maduración de las economías criminales: variables claves.

Fuente: FIP (2016, p. 13)

enfoques de derechos pasa por la revisión de la realidad compleja, informativa, de regulación y sistematización que deben tener como elementos de enlace los preceptos planteados por la justicia especial para la paz. Es en esencia, amén del juzgamiento de los actores que de manera voluntaria se acercan a resolver o dirimir los casos tratados en dichas salas, igualmente, la población tendrá un espacio en una justica que por ahora, sigue de forma mayoritaria, dirigida a los actores involucrados directamente en el conflicto. "Los procedimientos jurídicos y 
los protocolos institucionales están más diseñados para la confrontación que para la negociación" (Vélez 2015, p. 126).

\begin{abstract}
1) Según nuestro conocimiento, no hay estudios sobre el papel de la mujer en el Post - conflicto. 2) Hay pocos trabajos de investigaciones sobre el papel de la mujer en el conflicto colombiano. 3) La mayoría de estudios que se han realizado relacionados con este tema han sido de tipo cualitativo. 4) Se requieren más estudiantes que analicen diferentes dimensiones de la mujer en el conflicto y en el post - conflicto colombiano y, por último, 5) Es indispensable diseñar propuestas de intervención en las que se empodere a la mujer de cara a la investigación socio - política del país, de modo que sean capaces de participar activamente en la comunidad acogida. (Romero y Contreras, 2015, pp. 90-91)
\end{abstract}

Lo anterior se debe dar en igual sentido a la hora de evaluar las temáticas que rodean los casos de justicia especial para la paz referentes al medio ambiente y los derechos humanos, toda vez que se considera que la justicia ordinaria es capaz de solventar los hechos generados en el conflicto sobre ellos. Es un acierto para la discrecionalidad de los magistrados, la sala y el propio sistema de justicia colombiano el poder contemplar otras formas de concebir los problemas del conflicto desde los actores que más lo han sufrido. Es decir, que se espera que estos frentes sean igualmente evaluados, seguidos y controlados para sacar el máximo provecho de lo que generen. "Esta unidad trabajará tres temas: delitos de violencia sexual, daño ecológico producto del conflicto armado y reclutamiento y utilización indebida de menores de edad" (Redacción de Paz, 2018).

Es importante realizar una comparación entre las tres formas de justicia integradas y por separado, considerando de paso la posibilidad de que se pueda abastecer cada una de ellas en la medida en que se aprecia la complementariedad que tienen entre sí. A este ritmo, no se hablará de una sola justicia del conflicto o posconflicto, sino de una serie de argumentos con la cual desarrollar una justicia conforme a las condiciones del país. En este sentido, se abre espacio para grupos delincuenciales e incluso reincidentes o bandas que no gocen de dicha justicia y que aún sigan combatiendo, alejados de cualquier posibilidad de hacer parte de algún proceso de negociación o desmovilización.

\section{CONCLUSIONES}

En Colombia se ha hecho la tarea de ir construyendo una hoja de ruta jurídica para atender las diversidades del conflicto y posconflicto. Sin embargo, no existe una estructura a largo plazo que explique la evolución de estos fenómenos o formas de justicia. Por ende, el primer punto que se debe considerar es que efectivamente, se ha hecho la labor, por lo menos al pasar del diagnóstico a la comprensión del conflicto y las posibles formas para atender a este desde el aparato judicial, en algunos casos con la justicia ordinaria o bajo la posibilidad de crear justicias 
particulares para estos temas. Es por ello que se debe hacer una labor para destacar la estructura de las formas de justicia.

Conforme a los propósitos planteados en el marco del posconflicto en Colombia, la justicia especial para la paz, al igual que la justicia transicional, presentan una serie de tópicos que requieren análisis de cara a su correlación o divergencia frente a los impactos y resultados que traen ambas con respecto a lo pactado y esperado del proceso de paz. La conjugación de los métodos exploratorios, descriptivos y explicativos sirve de criterio para acercarse a dichas temáticas, puesto que la disposición de las metodologías pasa por la revisión de los ejemplos internacionales en los que se han desarrollado procesos como el colombiano.

Es fundamental acercarse a la justicia especial para la paz, las salas, magistrados y enfoques de políticas públicas con enfoques de derechos, jurídicas, poblacionales o territoriales. En este caso, se debe exponer que la justicia especial para la paz supera los reductos de la justicia ordinaria y se ubica en la instalación de políticas públicas encaminadas a desarrollar los preceptos abocados en dicha forma de justicia. En este caso, son las políticas públicas las llamadas a poner en evidencia los impactos y resultados de las salas de derechos ambientales, humanos y de género. En este caso, se deben agregar las políticas públicas con enfoque de paz, cubiertas en dichos enfoques.

\section{REFERENCIAS}

Bassiouni, M. (2007). Los principios de Chicago sobre Justicia transicional. Un proyecto conjunto del "International Human Rights Law Institute", "Chicago Council on Global Affaire", "Istituto Superiore Internazionale di Scienze Criminali" y la "Association Internationale de Droit Pénal". Instituto Interamericano de Derechos Humanos. Recuperado de https://biblioteca.iidh-jurisprudencia. ac.cr/index.php/documentos-en-espanol/ verdad-justicia-y-reparacion/1312-los-principios-de-chicago-sobre-justicia-transicional/ file

Bautista, S. (2017). Contribuciones a la fundamentación conceptual de paz territorial. Revista Ciudad Paz-ando, 10(1): 100-110.

Calderón Rojas, J. (2016). Etapas del conflicto armado en Colombia: hacia el posconflicto. Latinoamérica, 62(1): 227-257.

Caramès, A (2009). DDR2008: análisis de los programas de desarme, desmovilización y reintegración de ex combatientes existentes en el mundo durante 2008. Barcelona, España: Escola de Cultura de Pau.

Carrillo Ballesteros, J. G. (2015). Los derechos humanos de las víctimas en el marco de la justicia transicional en Colombia. DIXI(21), 9-26.

Castillejo Cuéllar, A. (2014). La localización del daño: etnografía, espacio y confesión en el escenario transicional colombiano. Horizontes Antropológicos, 20(42), 213-236. Recuperado de http://www.scielo.br/pdf/ha/v20n42/09.pdf

Consejo de Seguridad Naciones Unidas S/2004/616. El Estado de derecho y la justicia de transición en las sociedades que sufren o han sufrido conflictos Informe del Secretario General. Distr. General 3 de agosto de 2004 Español Original: inglés.

Delgado Barón, M. (2011). Una justicia transicional sin transición: verdad, justicia, reparación y reconciliación en medio del conflicto. Revista 
Análisis Internacional, 1(4), 53-67. Recuperado de https://revistas.utadeo.edu.co/index.php/ RAI/article/view/86

Duque Morales, C. R., y Torres Restrepo, L. M. (2015). Las garantías de no repetición cómo mecanismo permanente para la obtención de la paz. Universidad Estudios Bogotá (12): 269-290. Recuperado de https:// cienciasjuridicas.javeriana.edu.co/docum ents/3722972/6187126/13+Duque-Torres. pdf/8217f4c5-f3e9-4ec1-9e3d-d7a9bf43b0d9

Fundación Ideas para la Paz (FIP) (2016). Economías criminales en clave de posconflicto. Tendencias actuales y propuestas para hacerles frente. Serie Notas Estratégicas. No 1. Bogotá: FIP.

García Acuña, Y. (2012). Las víctimas del conflicto armado en Colombia frente a la ley de víctimas y otros escenarios de construcción de memorias: una mirada desde Foucault. Justicia Juris, 8(2), 74-87.

Garzón Buenaventura, E. F. (2013). Globalización del derecho, fetichismo legal: El velo de los derechos humanos. Verba Iuris (30), 169-181.

Goldstein, J. S. (2001). War and Gender: How Gender Shapes the War System and Vice versa. Nueva York. Cambridge University Press.

González Chavarría, A. (2010). Justicia transicional y reparación a las víctimas en Colombia. Revista Mexicana de Sociología, 72(4), 629-658.

Grasa, R. (2016). Los retos de la gestión de la violencia directa en el pos acuerdo. El debate sobre desarme, desmovilización, reintegración y reforma del sector de seguridad. Análisis. Recuperado de https://library.fes.de/pdf-files/ bueros/la-seguridad/12513.pdf

Gutiérrez Ramírez, L. M., y Rodríguez Rodríguez, J. (2013). Una comisión de la verdad en el modelo colombiano de justicia transicional: aproximación a través de la historia reciente y la experiencia comparada. Jurídicas, 2(10), 40-60.
Hernández Pulgar, R. C. (2011). La justicia transicional en el marco de los procesos de paz en Colombia. Revista Academia Libre, 8(9), 51-64.

Ibarra Padilla, A. M. (2016). Justicia transicional: la relación Derecho - Poder en los momentos de transición. Revista de Derecho (45), 237-261.

Jaramillo Marín, J., y Delgado Barón, M. (2011). "Deber de memoria" y "razones de olvido" en la justicia transicional colombiana. Análisis político (71), 129-147.

Jiménez Ocampo, S. (2008). Etnografía y crisis: algunos debates y una práctica de investigación en contextos de violencia. Nómadas, (29), 34-49.

Lopera Morales, J. J. (2011). Aproximación a la Justicia Transicional: interrogantes sobre su aplicabilidad en Colombia. Revista electrónica Diálogos de Derecho y Política, 7(2):91-103. Recuperado de https://aprendeenlinea.udea. edu.co/revistas/index.php/derypol/article/ download/11064/10146

Medina, M. A. (2018, marzo 1). "Un buen economista debe ser un buen economista de género", Andrew Morrison. El Espectador. Recuperado de https://www.elespectador.com/economia/ un-buen-economista-debe-ser-un-buen-economista-de-genero-andrew-morrison-articulo-741980

Montaño V. S., y Aranda, V. (2006). Reformas constitucionales y equidad de género. Informe final. Seminario Internacional. Santa Cruz de la Sierra, 21, 22 y 23 de febrero de 2005. Unidad Mujer y Desarrollo. CEPAL. Naciones Unidas. Serie seminarios y conferencias. (47).

Muñoz García, C. Y. (2013). Reflexiones sobre justicia transicional en Colombia: tensiones entre la justicia y la paz. Jurídicas, 2(10), 61 -86.

Niño López, L. F. (2016). Justicia transicional: principios de Chicago comparados al proceso de paz en Colombia. Revista Academia E Derecho, 7(13), 143- 184. 
ONU (2014). Justicia transicional y derechos económicos, sociales $y$ culturales. Nueva York y Ginebra: ONU

Orjuela Ruiz, A. y Lozano Acosta, C. (2012). La indeterminación del campo de la justicia transicional en Colombia. Revista Estudios Socio-Jurídicos 14(1): 255-281.

Orozco, M. (1998). De la negociación a la adaptación: los avances de los estudios sobre resolución de conflictos (Documento de trabajo presentado a la Escuela de Relaciones Internacionales de UNA - Ciencias Políticas) Universidad de Costa Rica.

Palacios Aguilar, L.E.H., Asprilla Valencia, S., y Vergara Mosquera, G. S (2017, enero-junio). La justicia transicional en Colombia desde los estándares internacionales de protección de derechos humanos. Summa Iuris, 5(1), 103-129.

Pérez Pérez, T. H. (2013). La justicia transicional y el caso colombiano: El derecho a la verdad como pilar fundamental para lograr la justicia y la reparación. Suma de Negocios, 4(1), 9-20.

Pfeiffer, S. (2014). Infraestructura de Paz en Colombia. Berlin: Berghof Foundation. Recuperado de https://www.berghof-foundation.org/ fileadmin/redaktion/Publications/Other_ $\mathrm{Re}$ sources/20141015_Pfeiffer_PI_Colombia_es.pdf

Reconciliación Colombia (2014, noviembre 14). Colombia llegó a 7 millones de víctimas. Recuperado de http://reconciliacioncolombia.com/web/ historia/1879/colombia-llego-a - 7 - millones-de-victimas

Redacción de Paz (2018, febrero 12). Posesionados fiscales de Unidad de Investigación y Acusación de la JEP, s.v. Paz. El Espectador. Recuperado de https://www.elespectador. com/noticias/paz/posesionados-primeros-fiscales-de-unidad-de-investigacion-y-acusacion-de-la-jep-articulo-738801

Rodríguez Rodríguez, C. (2015). Posconflicto y justicia transicional en Colombia: balan- ce de nuestra experiencia. Hallazgos, 8(5), 137-159.

Rodríguez Montenegro, G. P. (2011). Los límites del perdón. Notas sobre la justicia transicional en Sudáfrica, Centroamérica y Colombia. Justicia Juris., 7(2), 52-66.

Roldán Castellanos, L. (2013). La inclusión laboral de los desmovilizados del conflicto: auténtico mecanismo emancipador de la violencia en Colombia. Univ. Estud., (10), 107-123.

Romero, K., y Contreras, E. (2015). Revista teórica sobre el post - conflicto: Una oportunidad para empoderar a mujeres víctimas de desplazamiento. Cultura, Educación y Sociedad, 6(1), 79-92.

Sabogal Murcia, L. (2017). La significación del poder político y la acción en la justicia transicional colombiana: hacia la búsqueda de la paz en Colombia. Ágora U.S.B., 17(1), 211-224. Recuperado de http://www.scielo.org.co/scielo. php?pid $=$ S1657-80312017000100012Escript $=$ sci_abstract Etlng=es

Salas Salazar, L. G. (2016). Conflicto armado y configuración territorial: elementos para la consolidación de la paz en Colombia. Bitácora, 26(2), 45-57.

Theidon, K. (2000). Reconstrucción de la masculinidad y reintegración de excombatientes en Colombia. Universidad de Harvard. Departamento de Antropología. Series Working Paper FIP (5). Fundación Ideas para la PAZ

Torregrosa Jiménez, R., Torregrosa Jiménez, N., y Manrique Soacha, C. (2015). Las tendencias de investigación en el campo de la justicia transicional en Colombia. Revista Republicana (18), 87-111. Recuperado de http://ojs.urepublicana.edu.co/index.php/revistarepublicana/ article/view/209

Uprimny, R., y Saffon, M. P. (2007). Usos y abusos de la justicia transicional en Colombia. En Seminario Internacional de Paz y Responsabilidad en 
Transiciones de Conflictos Armados (pp. 165-195). Bogotá, Colombia: Universidad del Rosario.

Valencia Agudelo, G. D., y Mejía Walker, C. A. (2010). Ley de justicia y paz, un balance de su primer lustro. Perfil de Coyuntura Económica (15), 59-77.

Vélez Gutiérrez, L. F. (2015). Justicia transicional en Colombia: hacer justicia o negociar la paz. Estudio comparativo. Cuadernos de Derecho Penal. 111-137.
Ventura, M. (2016). Sistema Interamericano de Protección de Derechos Humanos: Necesidad y tipos de sanción aplicables en los procesos de justicia transicional. En Justicia, 30, 32-51.

Zúñiga Lindao, S. D. (2017). Análisis de la política pública de reintegración social y económica en el marco del proceso de justicia transicional en Colombia periodo 2013-2014. Revista Jurídica Mario Alario D’Filippo, 9(17), 95-131. 